\title{
CONTRIBUTION OF DEEP ELECTRICAL RESISTIVITY TOMOGRAPHY TECHNIQUE TO HYDROGEOLOGICAL STUDIES: CASES FROM AREAS IN KAVALA (NORTH GREECE)
}

\author{
Vargemezis G. ${ }^{1}$, Tsourlos P. $^{1}$ and Mertzanides I. $^{2}$ \\ ${ }^{1}$ Department of Geophysics, Aristotle University of Thessaloniki, 54124 Thessaloniki - Greece, \\ varge@geo.auth.gr,tsourlos@geo.auth.gr \\ ${ }^{2}$ Prefecture of Kavala,mertzan@gmail.com
}

\begin{abstract}
The most common geophysical method widely used in hydrogeological surveys concerning deep investigations (150-300m of depth) is the resistivity method and particularly the Vertical Electric Sounding (VES) using the Schlumberger array. VES interpretations assume 1D geoelectrical structure yet it is obvious that such an interpretation assumption is not valid in many cases where $2 D$ and $3 D$ geological features exist. In such cases the application of geoelectrical techniques which can provide both vertical and lateral information concerning the resistivity variations is required. Techniques such as the electrical resistivity tomography, mostly used for the $2 D$ and $3 D$ geoelectrical mapping of near surface applications can be adapted to be used for larger investigation depths provided that modified equipment (viz. cables) is used.

In the present paper, the application of deep electrical resistivity tomography (ERT) techniques is applied. ERT array of 21 electrodes, at a distance of 50 meters between them (total length 1000 meters) has been used in several studied areas located in the prefecture of Kavala (North Greece). In several cases near surface structure has been compared with VLF data.

The aim of the survey was to study in detail the geological-hydrogeological structure the area of interest in order to suggest the best location for the construction of hydrowells with the most promising results.

The 2D images of the geological structure down to the depth of at least 200 meters allowed the better understanding of the behaviour of layered geological formations, since in several cases resistivity values have been calibrated with data from pre-existing boreholes.
\end{abstract}

Key words: Electrical tomography, hydrogeology, hydrowells.

\section{Introduction}

Kavala is located in the northeast of Greece and is the easternmost prefecture of geographic region of Central Macedonia (Fig. 1). Its physical borders are the mountains of Paggaeo and Lekani from the north, and rivers Nestos and Strymonas, eastwards and westwards correspondingly. Agricultural production holds a significant role on local economy with almost a quarter out of the total active population being farmers cultivating approximately 50.000 acres of land. The increasing need for water resources mainly for irrigation, but also for tourist or industrial use, rendered water management a major priority issue for local authorities. Significant role in water management strategy is the suc- 


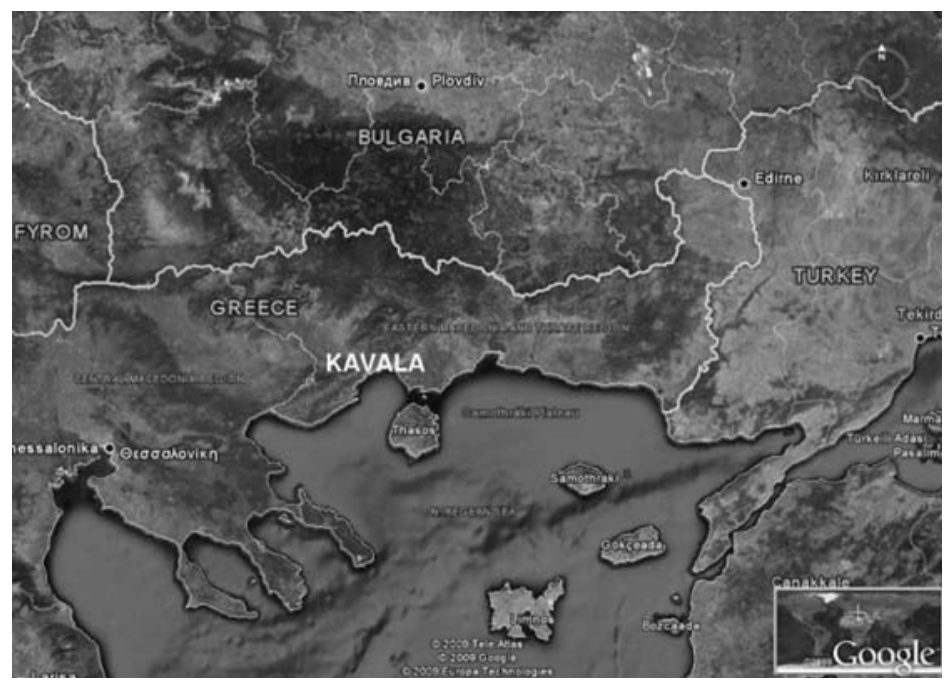

Fig. 1: Kavala is located at northeast of Greece and is the easternmost prefecture of geographic region of Macedonia.

cessful location of adequate water resources. Past experience in the exploration for underground water resources in the Prefecture of Kavala suggested that there were many cases where unsuccessful water drillings had a significant cost. In an attempt to reduce this cost the aid of geophysical methods was asked as a preliminary tool for suggesting the best location for the construction of hydrowells with the most promising results. This paper presents the results of geophysical investigation carried on by Laboratory of Applied Geophysics/School of Geology/Aristotle University of Thessaloniki (A.U.Th.), within the framework of a borehole drilling project, directed by Directorate of Land Reclamation/Prefecture of Kavala.

\section{General information}

Geomorphology of Kavala is dominated by the mountainous bodies of Paggaeo, Lekani and Symvolo. Among them, there are extended plain lands, eastwards (delta of river Nestos), in the middle (Philippi marsh) and westwards (Pieria basin). These are the main arable areas, with secondary ones lying between local semi-mountainous regions (Fig. 2).

Geology of Kavala is generally characterised by the presence of crystalline rocks, marbles and sedimentary rocks. Crystalline rocks (granites, granodiorites, gneisses) are fragmented and locally containing water reservoirs. Marbles are extensively karstificated and constitute the main underground fresh water reservoir of the area. Sediments are paleogenic, neogenic, and recent alluvial deposits, with interesting hydrogeology regime within the neogenic sandstones-conglomerates and pleo-pleistocenic deposits (Pliakas et al. 2002).

\section{Project objectives}

The water borehole drilling project of Kavala prefecture for 2006-2009, comprised of ten drillings and for six of them the contribution of prior geophysical exploration was requested. Three drillings were planned to provide irrigation water for the area between Paggaeo and Symvolo mountains (Pieria basin) and three in the semi-mountainous area at the surroundings of the city of Kavala. There water boreholes were planned mainly for irrigation use, but also for supporting domestic water supply, especially during the summer period. 


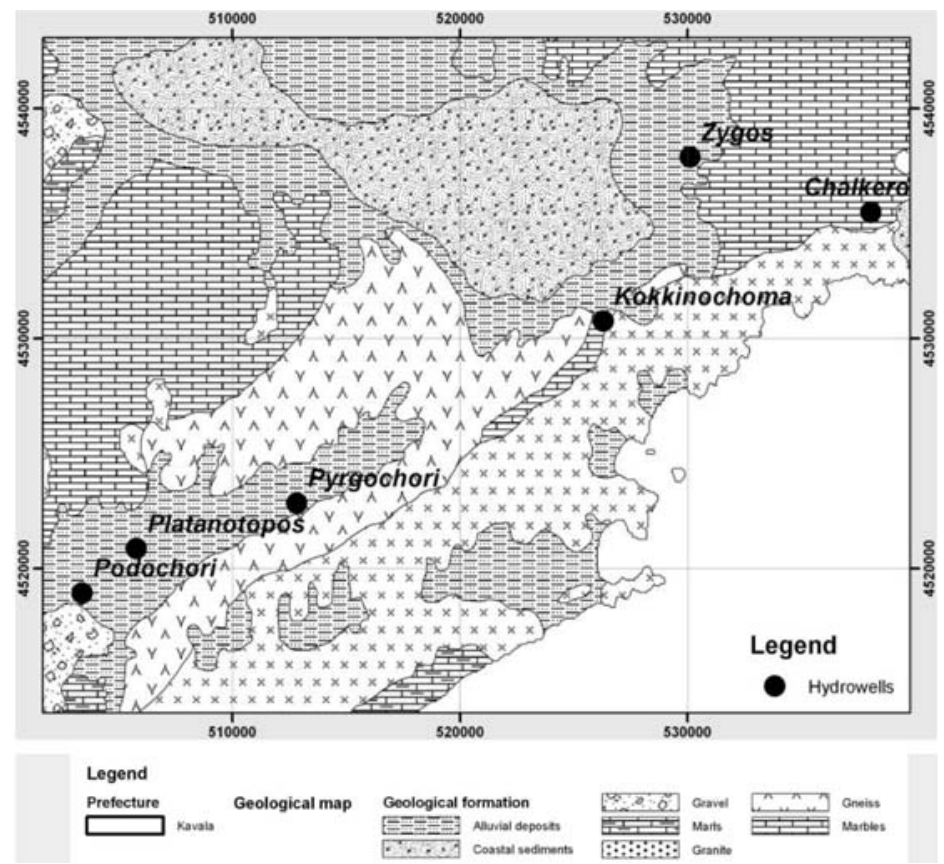

Fig. 2: General geomorphology and geology of prefecture of Kavala. The six suggested borehole drilling points are also shown.

The particular areas of interest were in the municipal departments of Pyrgochori, Podochori, Platanotopos in Pieria basin and Kokinochoma, Zygos and Chalkero. On Pyrgochori, Platanotopos and Zygos, irrigation water was transferred from many kilometres away, raising the cost of local agricultural production. On Podochori, Kokinochoma, Zygos and Chalkero the irrigation water supply was not adequate, resulting into reduced agricultural production. In Podochori, Pyrgochori and Chalkero, several unsuccessful drilling attempts were recorded in the past. A possible reason could be the absence of any particular hydrogeological or geophysical examination of the area.

The objective of the project was the search of the most promising and appropriate drilling location by adopting following step-by-step procedure. An initial examination of the local geological and hydrogeological conditions together with any relevant prior information is required in order to locate wider regions which can be favourable for positioning the well. A second step is to examine various other additional criteria which have to be taken into account such as: the land ownership regime of the area, accessibility of the potential areas, proximity to existing hydrowells, proximity to electric power supply, cost for water transfer etc. This required a very close multi-parametric examination of the areas of interest which resulted in limiting the selected candidate sites. So only after defining major and alternative sites of interest the geophysical investigation was carried out aiming to provide subsurface geological and hydrogeological information which will position with an increased detail the well in the most promising location.

\section{Geophysical survey}

In most of the areas where the authorities of the prefecture of Kavala were interested for additional water supply, underground water was expected in neogenic sediments as well as marble and metamorphic rocks. In several cases the thickness of sediments was estimated from surrounding wells but in other cases there was no prior information about the geological, hydrogeological status of the area. 


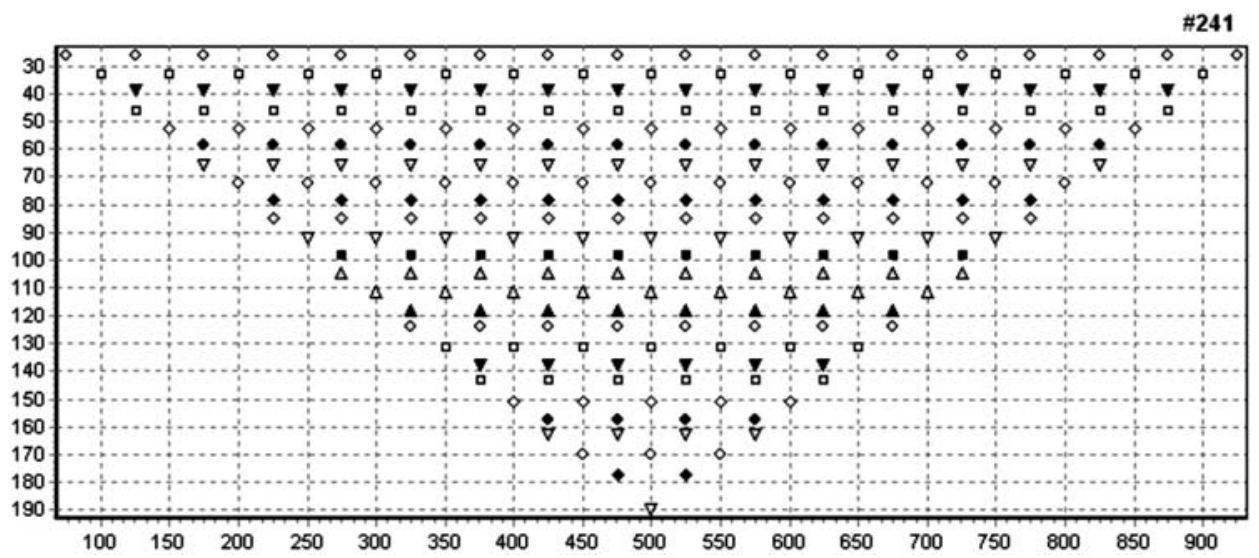

Fig. 3: Predicted distribution of location of apparent resistivity measurements, using the Dipole Dipole array with the proposed equipment.

Considering the factors of (a) hydrogeological structure, (b) cost of construction and (c) cost of exploitation of water boreholes, it stands that the average depth of interest is about 200-250 meters, especially in the prefecture of Kavala. In such a case the most widely used, low cost, geophysical method for such investigation depths is the Schlumberger vertical electrical sounding (VES), (Koefoed, 1979). To reach the depth of 250 meters, an experienced team needs more than one hour of field work, and the result is the 1D geoelectrical model below the fixed centre of the measuring array. Commonly, more than one VES soundings are carried out in an investigation site to cross-validate the findings. The main disadvantage of the VES procedure is that interpretation is carried out by considering earth layers as being horizontal (1-D model). Therefore more complicated (2-D, 3-D) geological structures not only cannot be predicted by the 1-D modelling procedure but actually can become a significant source of noise which can result in erroneous interpretation of the VES data.

In nature, the most common case of stratigraphy formed in sedimentary basins is the 2 or $3 \mathrm{D}$ one since strata are usually inclined or laterally ended. Because of this reason, in this paper, the application of 2D electrical resistivity tomography (ERT) (Dahlin, 2001) instead of 1D VES is suggested. Although this is perfectly feasible from a theoretical point of view the application of ERT is not common for such large investigation depths due to increased cable logistics required and for investigation depths of 200-250m, practically no commercially easy to use cables exist. The main difficulties for such cables arise from the fact that from one hand we need an appropriate resolution in order to describe adequately the subsurface but from the other hand we need to get the maximum investigation depth. A reasonable compromise between these two is to use a cable of 21 electrodes with the separation of 50 meters. A special multi-core cable like this with a total length of 1000 meters was constructed by the Geophysical Lab of AUTH. It consists of two special cable drums with 500 meters of multicore cable each, weighting aprox. 35 Kgrs each. The cable can be readily carried in the field and a crew of 4 persons can measure up to 3 sections in one day's work.

Since electrode line is settled on the field, different arrays can be measured using an automated ERT instrument with multiplexer. Geoelectrical data were obtained using a 10-chanel resistivity meter (IRIS INSTRUMENTS) with a 48 cable multiplexing ability. The arrays measured in this survey are the Dipole-Dipole and Wenner-Schlumberger arrays as arrays having electrodes at "infinity" are not practical to measure at such scales. 
The distance of current and potential electrodes for various separations was $1 n * a, 2 n * a$ and $3 n * a$ where $a$ is 50 meters and maximum $n$ was 8. A typical map of the measurements locations by the use of the parameters described above in the so-called pseudosection of apparent resistivity measurements is depicted in Figure 3. As it can be seen in Figure 3, although the electrode separation is 50 meters the design of the measurements selecting various combinations of current and potential electrodes can achieve more detailed investigation of the underground, resulting in the best resolution.

Interpretations were obtained by inverting data with an iterative smoothness constrain scheme (Kim, 2009) based on a finite element forward solver (Tsourlos, 1995). Elevation information was incorporated in the interpretation in order to correct data from topography effect.

The deep resistivity tomography has been applied in several places at the prefecture of Kavala in the frame of the project mentioned above. In every case the best location for the construction of the hydrowell was proposed according to the results of the ERT where the final interpretation was taking into account the general geological structure of the regional area and lithostromatography information from the surrounding area where it was available.

\section{ERT results-Drilling Data}

In the following paragraphs, the drilling information for every hydrowell is described as well as the result of the correspondent ERT profile in order to explain the decision that was made.

\section{- Pyrgochori borehole}

In Pyrgochori the two $1 \mathrm{~km}$ long ERT profiles perpendicular to each other were measured. These ERT profiles aimed to investigate the depth and the behaviour of the marble as the bedrock of the area, as well as the sedimentary deposits (Fig. 4). The profile of NE-SW direction showed a dipping of the bedrock most likely associated to a local basin (at 300-500 meters of the ERT section), and therefore the construction of the well has been proposed at that location.

Drilling operations were carried out on July of 2006 and stratigraphy was described by alterations of red clays, pebbles, sands, and conglomerates. Drilling stopped at 177 metres depth, because of a thick layer of green marl that was continuous for the last 24 metres. Production string and pumping test which followed resulted to water supply of more than 100 cubic metres per hour. Hydrostatic and pumping ground water levels were at 1.5 metres and 21 metres correspondingly (Fig. 4).

\section{- Podochori borehole}

In Podochori area, two (2) ERT almost parallel lines of an average direction of $305^{\circ}$ have been measured in order to investigate any lateral changes in the sedimentary formations as well as the depth to the bedrock (Fig. 5). Test drilling has been suggested to the second ERT line where a possible fault of the bedrock has been detected.

Drilling operations were carried out on October 2007. Lithology showed mainly alterations of clays (green, yellow, black, red), pebbles, marly conglomerates/sandstones/limestone and sandstones (Fig. 5). Drilling stopped at 220 metres, after a continuous layer of black clay that was found at 210 metres. Poor aquifers found on few thin layers of pebbles. Production string and pumping test followed resulted to a water supply of 20 cubic metres per hour. Hydrostatic and pumping ground water levels were at 58.5 metres and 165 metres correspondingly. It is noted that, in the same area there had been two unsuccessful drilling attempts in the past and the water supply of the existing boreholes never exceeded $30 \mathrm{~m}^{3} / \mathrm{h}$. 


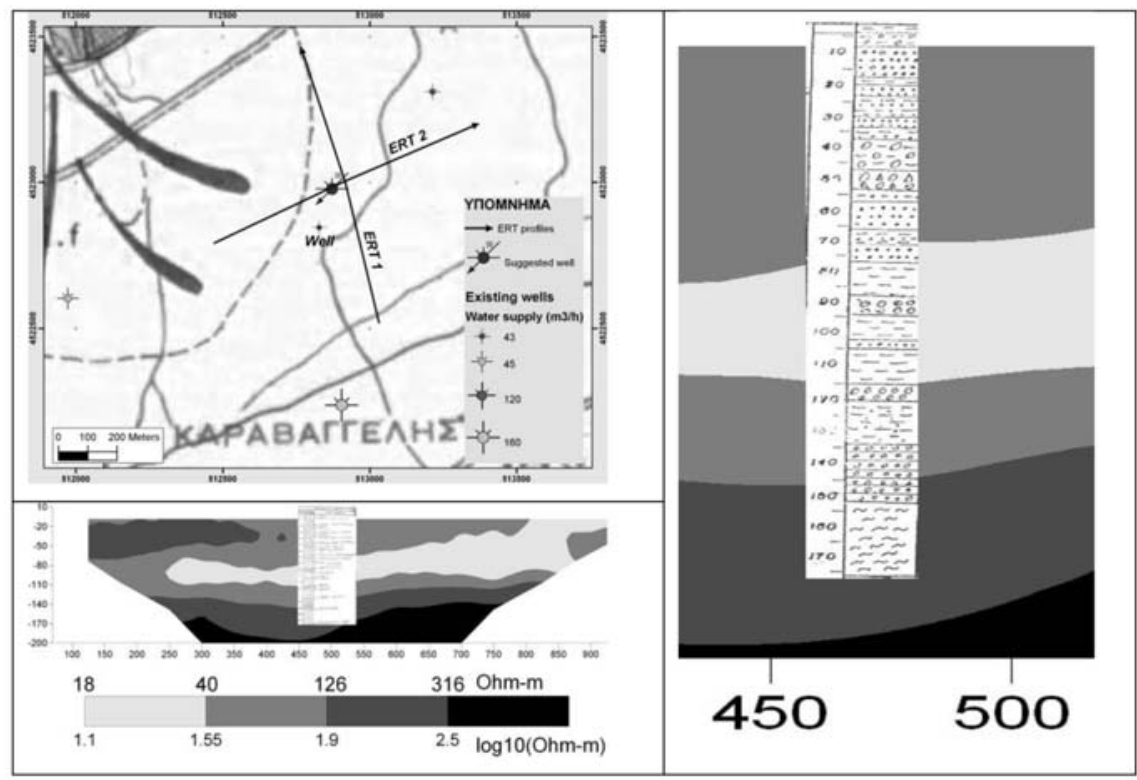

Fig. 4: Lithology log for Pyrgochori borehole. Inversion image refers to line ERT 2.

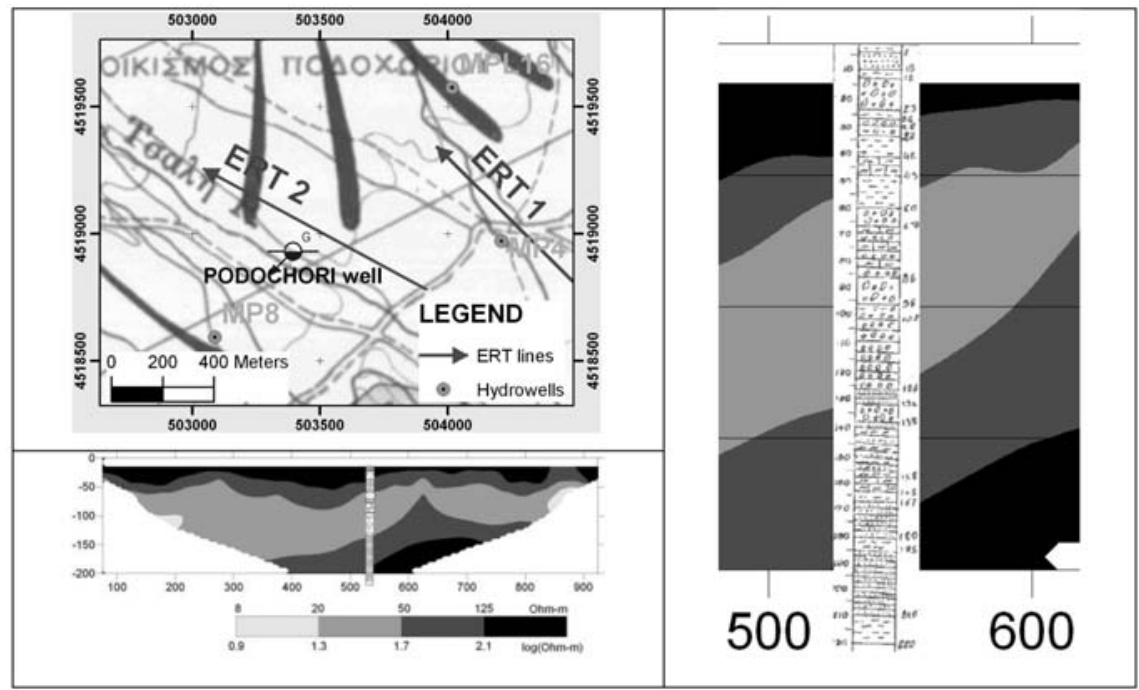

Fig. 5: Lithology log for Podochori borehole. Inversion image refers to ERT 2.

\section{- Platanotopos borehole}

The ERT line in Platanotopos area has been measured in a direction perpendicular to the contact of the marble formation with sediments in order to check the dipping of the marble (Fig. 6).

Water borehole have been suggested to the southern part of the profile since a very sharp dipping of the bedrock towards the south has been detected at the horizontal distance of 400 meters showing the existence of a fault. 


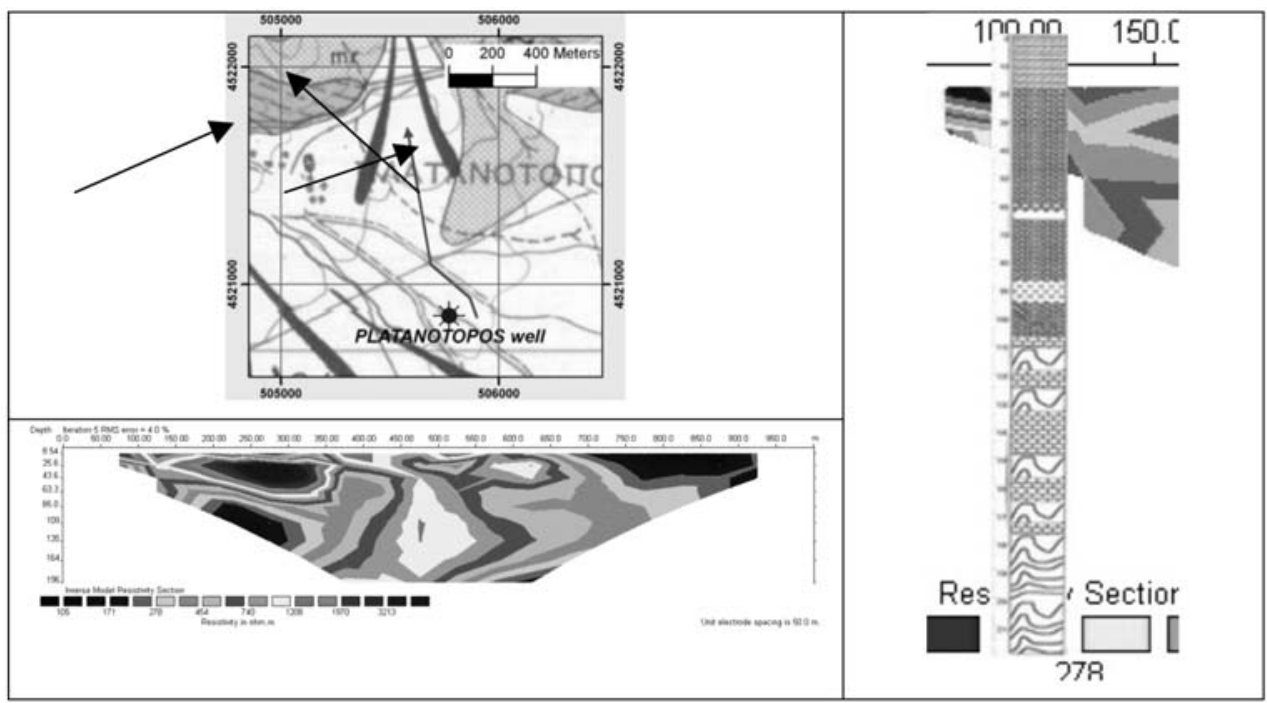

Fig. 6: Lithology log and tubing for Platanotopos borehole.

Drilling jobs carried out during August and September of 2008. For the first 100 metres, the known stratigraphy of the area was met, consisting of altered layers of pebbles, conglomerates and clays. But at 106 metres deep, where alterations of marbles and gneiss have been met, drilling paused because of a gap found. Good news was that this gap was a rich aquifer filled of big amounts of water, probable due to a fault bell. Casing of 10.5 inches diameter has been applied to the depth of 105 metres. Drilling continued with narrower cut inside ( 8.5 inches) until 220 metres depth, with alterations of marbles and gneisses. The pumping test was the second pleasant surprise: Continuous pumping by 150 cubic metres per hour, reduced the hydrostatic ground water level only for a meter: From 66.2 to 67.2 metres deep (Fig. 6).

\section{- Zygos borehole}

The target of the geophysical survey in the case of Zygos was the investigation of the nature of the sedimentary formations focused on the distribution of clay sediments. This, two ERT lines have been measured which were crossing each in order to extract information about the dipping of strata. Interpretation of geoelectrical data showed that the bedrock formation was deeper than 200 meters. Until 160 metres depth aquifers constituted by pebbles and gravel horizontally stratified were expected.

Drilling operations were carried out on November 2008. During the first 170 metres of drilling, alterations of clays (red, yellow, green), pebbles and conglomerates were found. Deeper, between 170-200 metres, fragmented layers of gneiss and conglomerates were met. Layers of conglomerates were rich water reservoirs as shown later by pumping test: More than 100 cubic metres per hour water supply and water level reduced from 35 metres (hydrostatic) to 43 metres deep (24 hours pumping) (Fig. 7).

\section{- Kokkinochoma borehole}

One ERT line has been measured in this area, aiming to investigate the lateral contact between the formations of gneisses and marble.

Drilling jobs carried out on November and December of 2008. The lithology was the expected: Gneisses and gneiss-schists, partly fragmented. Drilling stopped at 224 metres depth. Pumping test 


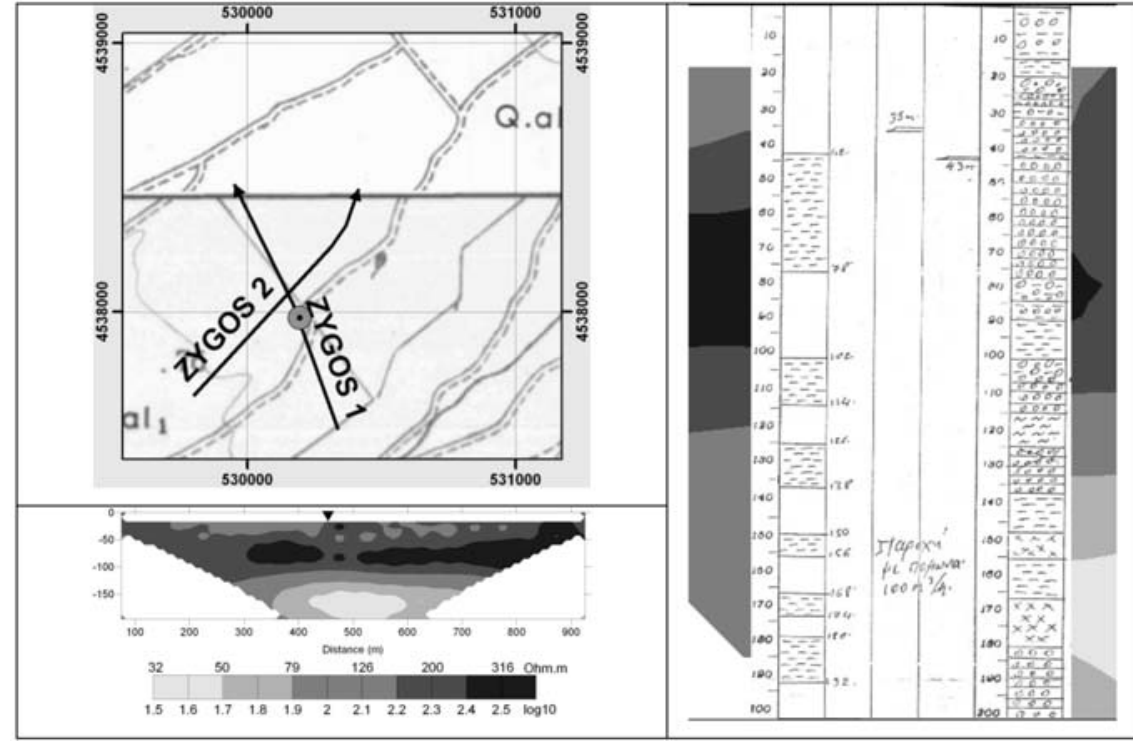

Fig. 7: Lithology log and tubing for Zygos borehole. Hydrowell's location is pointed with a black triangle on the ERT inversion image.

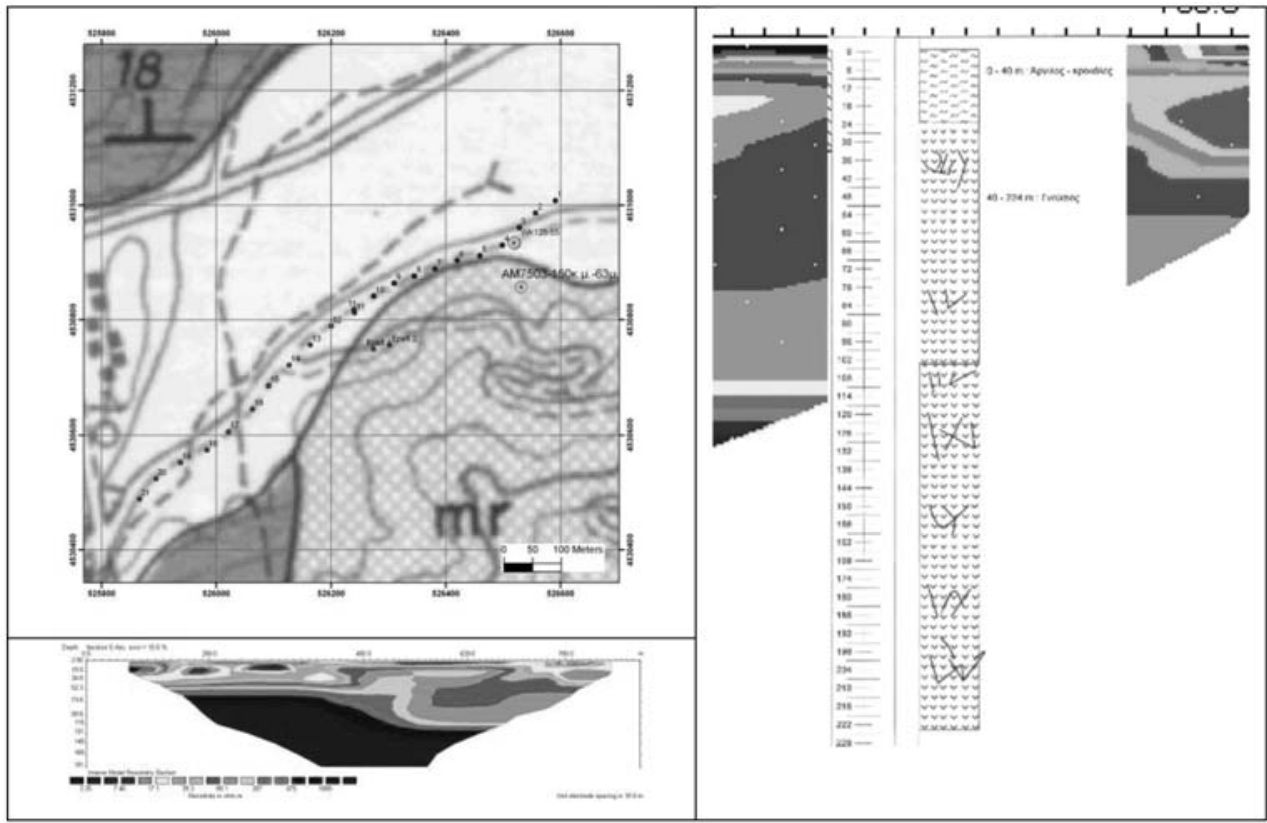

Fig. 8: Lithology log for Kokkinochoma borehole.

that followed, resulted to water supply of 50 cubic metres per hour. Hydrostatic and pumping ground water levels were at 15 metres and 88 metres correspondingly (Fig. 8). 


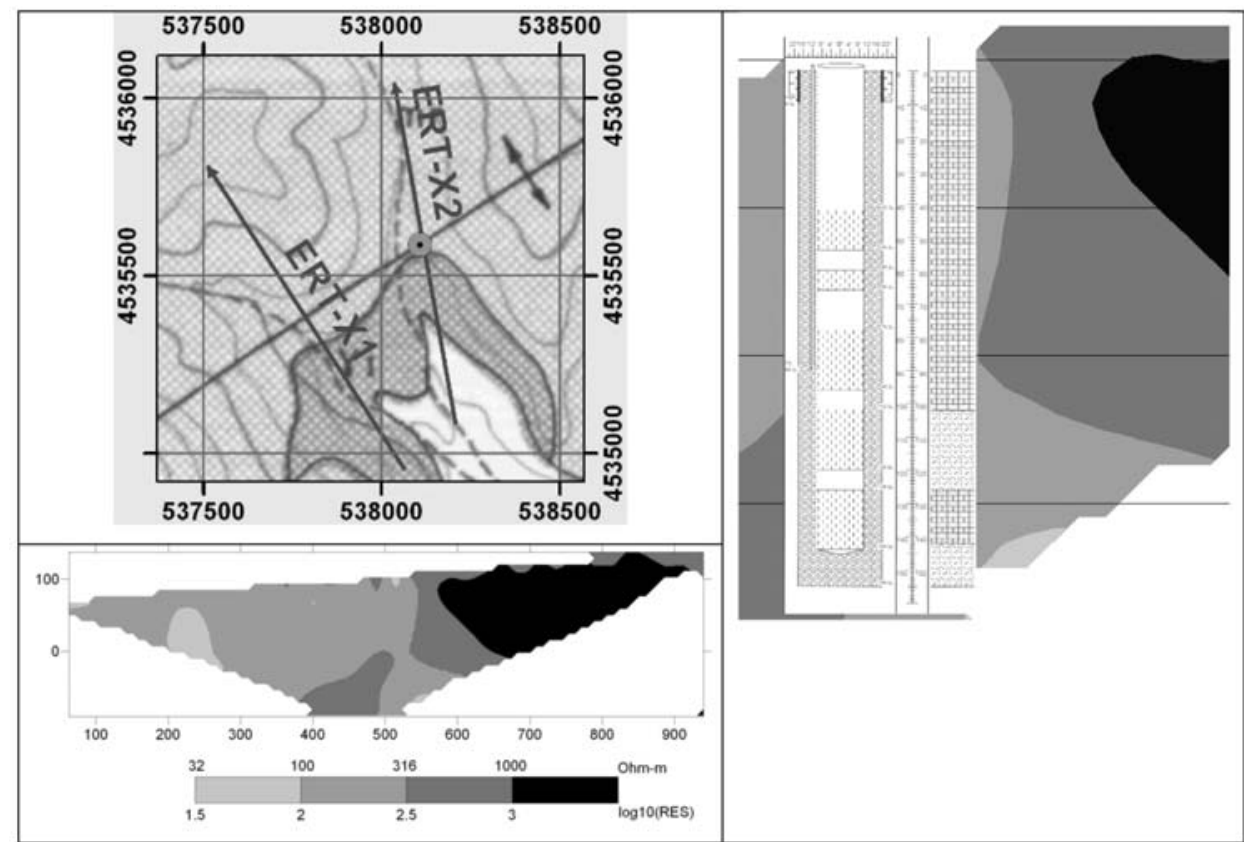

Fig. 9: Lithology log and tubing for Chalkero borehole. ERT inversion scheme refers to ERT-X2 line.

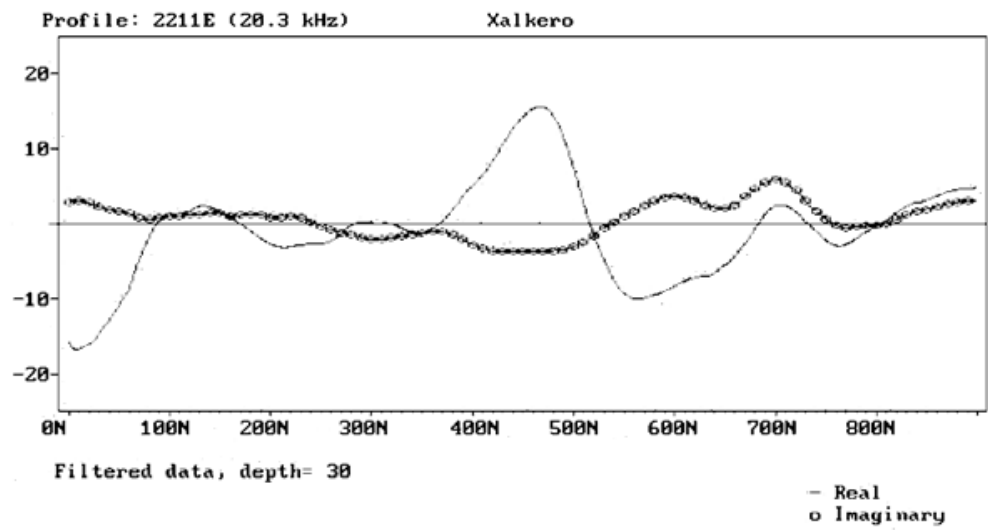

Fig. 10: VLF profile along with the ERT profile.

\section{- Chalkero borehole}

The target of the geophysical survey in this area, was (a) prospecting for possible detection of secondary porosity in the formation of marbles, (b) study of the contact between granite and marble and (c) study of the broad-crested anticline as it is characterized in the geological map of the area by IGME. Two ERT lines have been measured perpendicularly to the contact line. In addition, a VLF line has been measured at the same line where ERT-X2 has been realized, in order to provide more detailed information about lateral change noticed at the resistivity distribution as the inversion of the ERT data showed (Fig. 9). 
Drilling operations have been carried out on August and September of 2009. After 9 metres of mixed clays and conglomerates, fresh marble was found. The fragmentation was detected after the depth of 31 metres and continued with alterations of fresh and fractured rocks. At the depth of 100 metres, fragmented granodiorite was found and fragmented zones of marbles and granodiorites were continued until the depth of 152 metres. This zone is considered to be the one suggested by the resistivity and VLF survey as a conductive one and as it was proved it was an extremely rich water aquifer. Pumping test that followed resulted to water supply of more than 180 cubic metres per hour. Hydrostatic level was at depth 16.80 metres and pumping ground water level at 63.7 metres (Fig. 9).

It can be seen that VLF anomaly showing a faulting zone dipping to the beginning of the profile is totally in agreement with the ERT inversion.

\section{Discussion}

A discussion on the results of the present study, should not only contain "pure" scientific issues, concerning the ERT techniques applied, but also refer to the objectives defined on section 3. Following these objectives, it should be mentioned that:

- In all six cases, drilling points suggested, resulted to productive boreholes.

- In all six cases, there was relative to total lack of hydrogeological information, adequate to drive to documented choice of drilling points.

- In two cases (Platanotopos and Chalkero) the amount of underground water supply, was far beyond expectations.

According to these, the borehole drilling project of Directorate of Land Reclamation/Prefecture of Kavala, was strongly supported by the geophysical research, it became more efficient and contributed to the welfare of local societies.

On the other hand, drilling data crosschecked to ERT profiles, offered a valuable "feedback" to interpretation given, contributing to better understanding the potentials and limitations of the applied techniques.

\section{Acknowledgements}

We would like to thank Mr. C. Tsobanoglou, head of Directorate of Land Reclamation/Prefecture of Kavala, for his contribution to organising issues.

\section{References}

Dahlin T., 2001.The development of DC resistivity imaging techniques. Computers \& Geoscience, 27, (9), 1019-1029.

Directorate of Land Reclamation/Prefecture of Kavala, 2008. Record Room, Kavala. National Statistical Service of Greece 2009. Arable land and areas of Greece: 2000-2007 (provisional data). Press Release NSSG, Athens.

Koefoed, O. (1979). Geosounding principles, 1, Resistivity Sounding Measurements. Elsevier, Amsterdam.

Kim, Y.H., 2009. DC2Dpro - User's Manual, KIGAM, Daejon, Korea.

Pliakas, F., Diamantis, I. and Petalas., C., 2002. Hydrogeological research for sufficiency and quality of drinking water in municipalities of Kavala - Some management suggestions. Proceedings of the 6th National Hydrogeological Congress, Xanthi, 413-426.

Tsourlos P., 1995. Modeling interpretation and inversion of multielectrode resistivity survey data. Ph.D. Thesis, University of York. 